\title{
Superação de dormência na qualidade de sementes e mudas: influência na produção de Senna multijuga (L. C. Rich.) Irwin \& Barneby
}

\author{
Graziela PIVETA², Vanessa Ocom MENEZES², Daniele Cardoso PEDROSO³, Marlove Fátima Briāo \\ MUNIZ ${ }^{4}$, Elena BLUME ${ }^{5}$, Angélica Polenz WIELEWICKI ${ }^{6}$
}

\begin{abstract}
RESUMO
O objetivo deste trabalho foi determinar a qualidade fisiológica e sanitária de sementes de Senna multijuga (L. C. Rich.) Irwin \& Barneby relacionada aos métodos de superação de dormência e à interferência na produçáo de mudas. As sementes foram submetidas aos seguintes métodos: imersão em água fervente, as sementes foram imersas em água, com temperatura de $100^{\circ} \mathrm{C}$, até esfriar, por 24 horas; escarificação ácida, onde as sementes foram imersas em ácido sulfúrico $\left(\mathrm{H}_{2} \mathrm{SO}_{4}\right)$ a $90 \%$, por 10 e 20 minutos, e testemunha (sem tratamento). Foram realizados os testes de sanidade, germinaçáo, tetrazólio e avaliação da qualidade das mudas. O delineamento experimental foi inteiramente casualizado. Para a avaliação da germinação foi utilizado um esquema fatorial (4X 2), com quatro métodos de superação de dormência X dois fotoperíodos, para os substratos rolo-depapel e vermiculita. A escarificaçáo ácida constituiu-se no método mais eficiente para a superação da dormência das sementes de Senna multijuga. Penicillium sp. e Aspergillus sp. tiveram sua incidência aumentada quando o tegumento foi danificado pela escarificaçáo ácida por 20 minutos. O controle de Fusarium spp. aumentou gradativamente com o aumento do tempo de exposição ao ácido sulfúrico.
\end{abstract}

PALAVRAS-CHAVE: Espécies florestais; fungos; substrato; fotoperíodo.

\section{Overcoming of dormancy in the quality of seeds and seedlings: influence in the production of Senna multijuga (L.C. Rich.) Irwin \& barneby}

\section{ABSTRACT}

The objective of this work was to determine the physiological and sanitary quality of Senna multijuga seeds related to the methods of dormancy overcoming and the influence on the seedlings quality. The seeds had been submitted to the following methods :immersion in water fervent, the seeds had been immersed in water, at $100^{\circ} \mathrm{C}$, until cooling for 24 hours; acid escarification, where the seeds had been immersed in sulfuric acid $\left(\mathrm{H}_{2} \mathrm{SO}_{4}\right) 90 \%$, for 10 and 20 minutes, and control (without treatment). The tests of sanity, germination and tetrazolium had been carried through, and were evaluated the quality of the seedlings. For the germination of the evaluation an factorial project was used (4 X 2), with four methods of dormancy X two light periods, for substrate paper and vermiculite. The acid scarification consisted in the method most efficient for the dormancy of Senna multijuga seeds. Penicillium sp. and Aspergillus sp. they had for its increased incidence when the seed coast was damaged by the acid scarification for 20 minutes. The control of Fusarium spp. increases gradual with the increase of the time of sulfuric acid exposition.

KEY WORDS: Forest species; fungi; substrate; light.

\footnotetext{
1 Universidade Federal de Santa Maria - UFSM, E-mail: grazipiveta@yahoo.com.br

2 Universidade Federal de Santa Maria - UFSM, E-mail: vanebutterfly@hotmail.com

${ }^{3}$ Universidade Federal de Santa Maria - UFSM, E-mail: danibioufsm@yahoo.com.br

${ }^{4}$ Universidade Federal de Santa Maria - UFSM, E-mail: marlove@smail.ufsm.br

${ }^{5}$ Universidade Federal de Santa Maria - UFSM, E-mail: eblume@smail.ufsm.br

${ }^{6}$ Ministério da Agricultura, E-mail: angelicapw@gmail.com.br
} 


\section{INTRODUÇÃO}

Senna multijuga, conhecida como "aleluia", pertence à família das Mimosaceae. É considerada uma espécie pioneira e secundária inicial ou clímax exigente de luz, sendo indicada para reflorestamento em áreas degradadas de preservaçáo permanente (Carvalho, 2003).

A espécie é muito procurada por animais da família Dasypodidae, que fazem buracos na base do tronco em busca de ninfas de insetos, que ficam escondidas no solo para seu alimento (Carvalho, 2003).

Para a exploração racional das potencialidades das espécies nativas na recuperação de ambientes, é de suma importância o estudo da qualidade de sementes das espécies, bem como a melhor maneira de produção de mudas.

O desenvolvimento de métodos para a avaliação rápida da qualidade fisiológica das sementes pode auxiliar na tomada de decisão quanto ao uso ou descarte de lotes destinados à conservaçáo e ou produção de mudas, principalmente para espécies cujo período para germinação é demasiadamente longo.

A qualidade fisiológica das sementes é avaliada por meio de parâmetros fundamentais, como a viabilidade e o vigor. Os testes de vigor têm sido utilizados para identificar diferenças na qualidade fisiológica de lotes que apresentem poder germinativo semelhante e têm sido utilizados para complementar as informaçóes fornecidas pelo teste de germinação (Carvalho e Nakagawa, 1988).

Existe grande variaçáo na resposta das sementes à luminosidade: a germinação das sementes de algumas espécies é inibida pela luz, enquanto que em outras, a germinação é estimulada. A germinação está relacionada também com a quantidade de luz; esta, durante a maturação da semente, é um importante fator controlador da germinação. Geralmente os fatores luz e temperatura têm efeito interativo sobre a germinação de sementes fotossensíveis (Nassif et al., 1997).

A maioria das sementes germina quando colocada em condiçōes ambientais favoráveis. Nessas condiçōes, quando a germinação não ocorre, as sementes são consideradas dormentes (Kramer e Kozlowski, 1968).

Para Bewley (1997), a dormência pode ser interpretada como falha de uma semente intacta e viável em germinar sob condiçôes aparentemente favoráveis de germinação. A dormência das sementes é um dos principais problemas para produção de mudas de espécies florestais nativas, principalmente de leguminosas, que apresentam tegumentos impermeáveis à água (Bianchetti e Ramos, 1982).

A qualidade sanitária é um dos mais importantes aspectos na produção de mudas, pois os microrganismos podem causar anormalidades e lesôes nas plântulas, bem como deterioração de sementes, principalmente em testes realizados em incubadoras ou germinadores, que dáo condiçôes ideais para o desenvolvimento e a disseminaçáo de alguns dos fungos, causando apodrecimento das sementes e dificultando o diagnóstico correto da qualidade fisiológica do lote. Carneiro (1986), afirma que os maiores problemas ligados às doenças ocorrem durante a germinação e formação de mudas em viveiro e, geralmente, são causados por fungos.

O presente trabalho teve como objetivo determinar a qualidade fisiológica e sanitária de sementes de aleluia (Senna multijuga) relacionada aos métodos de superaçáo de dormência e a influência na qualidade das mudas produzidas.

\section{MATERIAL E MÉTODOS}

O trabalho foi conduzido nas instalaçóes do Laboratório de Pesquisa em Fitopatologia do Departamento de Defesa Fitossanitária da Universidade Federal de Santa Maria e no Laboratório de Análise de Sementes Florestais e Casa de Vegetação do Centro de Pesquisa de Recursos Florestais - FEPAGRO-Florestas, no distrito de Boca do Monte, município de Santa Maria-RS. As sementes utilizadas foram procedentes da FEPAGRO-Florestas.

Os tratamentos realizados para a superação da dormência foram: imersão em água fervente, as sementes foram imersas em água, com temperatura de $100^{\circ} \mathrm{C}$, até esfriar, por 24 horas (Medeiros, 2001); escarificação ácida, onde as sementes foram imersas em ácido sulfúrico $\left(\mathrm{H}_{2} \mathrm{SO}_{4}\right)$ a $90 \%$, por 10 e 20 minutos e testemunha (sem tratamento). Após, os tratamentos, as sementes foram avaliadas pelos seguintes testes,

Teste de sanidade realizado por meio do método "Blotter test", em amostras de 100 sementes, divididas em 4 subamostras, colocadas em caixas de plástico tipo "Gerbox", sobre três folhas de papel filtro esterilizadas e umedecidas com água destilada e esterilizada. A incubação foi realizada em estufa, à temperatura de $25^{\circ} \mathrm{C}$, em regime de 12 horas de iluminação com lâmpadas fluorescentes, alternadas com 12 horas de escuro, durante sete dias. Após este período, foram avaliados os microorganismos presentes nas sementes, com auxílio de microscópios esterescópio e ótico.

Teste de germinação composto de quatro repetições de 50 sementes, que foram colocadas entre vermiculita (EV) e em rolo de papel (RP). O substrato vermiculita foi colocado em caixas plásticas tipo gerbox, umedecido com água destilada até atingir $60 \%$ da capacidade de retenção de água, e o substrato de rolo de papel foi umedecido com água destilada equivalente a 2,5 vezes o peso do papel seco. As sementes foram colocadas no germinador à temperatura de $25^{\circ} \mathrm{C}$, com fotoperíodo de 12 e 24 horas (Brasil, 1992). Para as contagens, foram consideradas plântulas normais, anormais, sementes mortas e duras. 
Teste de tetrazólio as sementes foram escarificadas com o auxílio de uma lixa papel (80) no lado oposto ao embrião e submersas durante 14 horas em água destilada, a temperatura de $25^{\circ} \mathrm{C}$. Após hidratação, o tegumento e o endosperma foram removidos com o auxílio de uma lâmina e os embrióes imersos nas soluçóes de tetrazólio na concentração de $0,1 \%$, permanecendo incubados por 5 horas em estufa a $35^{\circ} \mathrm{C}$, no escuro. Após a incubação, os embriôes foram lavados com água destilada e seccionados longitudinalmente com lâmina. As avaliaçóes foram feitas com auxílio de microscópio estereoscópio, sendo elaborado um padrão de classificação das sementes, como viáveis (embriāo completamente colorido), intermediárias (as áreas coloridas representam a área mínima do embrião necessário para germinação normal) e inviáveis (embriāo não-colorido). $\mathrm{O}$ teste foi realizado com quatro repetiçôes de 25 sementes.

Para a avaliação da qualidade das mudas, o experimento foi conduzido em casa de vegetação, onde três sementes foram semeadas, em recipientes individuais (tubetes). Os recipientes foram preenchidos com substrato composto por uma mistura de solo do subsolo, casca de arroz e humus na mesma proporção. Aos 64 dias após a semeadura, foram realizadas as seguintes avaliaçóes: comprimento da parte aérea, foi medido com escalímetro milimetrado da distância entre a base do caule e o ápice do feixe de folhas, o resultado foi expresso em centímetro; comprimento de raiz, onde foi medida a distância entre o colo e a base da raiz com auxilio do escalímetro milimetrado e o resultado foi expresso em centímetro; altura total da planta, medida com o auxílio de um escalímetro milimetrado da distância entre a base da raiz e o ápice do feixe de folhas e o resultado foi expresso em centímetro, diâmetro do colo, medida com o auxílio de um paquímetro digital e o resultado foi expresso em centímetro; massa seca de mudas: as mudas foram lavadas em água corrente para retirar o resíduo de substrato retido nas raízes e entáo, deixadas para escorrer sobre papel absorvente. Logo após, as mudas foram acondicionadas em sacos de papel e colocadas na estufa a $70^{\circ} \mathrm{C}$ por 24 horas e então foram pesadas, determinando o peso total das mudas. $\mathrm{O}$ resultado foi expresso em gramas.

O delineamento experimental foi inteiramente casualizado. Para a avaliaçáo da germinação foi utilizado um esquema fatorial (4 x 2), com quatro métodos de superação de dormência x dois fotoperíodo. Para a avaliaçáo de sanidade, teste de tetrazólio e produçáo de mudas, foram considerados como tratamento apenas os métodos de superação da dormência. Os dados em percentagem foram transformados em arco sen $\sqrt{x} / 100$ e submetidos à análise de variância. A comparação de médias entre os diferentes métodos de superação de dormência e substrato foi realizado através do teste de Tukey a $5 \%$ de significância, e foi realizada análise de correlação linear entre as variáveis dos diferentes testes, utilizando-se o o pacote estatístico SANEST (Zonta e Machado, 1984).

\section{RESULTADOS E DISCUSSÃO}

Nas Tabelas 1 e 2, foi verificado interaçôes significativas entre os métodos de superaçáo de dormência e fotoperíodos para os substratos rolo-de-papel e vermiculita, indicando que existe uma combinação entre estes dois fatores, ou seja, o efeito dos tratamentos pode sofrer a interferência do fotoperíodo utilizado para as variáveis estudadas.

$\mathrm{O}$ uso da água quente reduziu a viabilidade das sementes de Senna multijuga, com valores nulos para plântulas normais (Tabela 1). Aliado a isto, este tratamento proporcionou uma alta porcentagem de sementes mortas (73\%). Resultados semelhantes foram obtidos por Rodrigues et al. (1990), onde os autores verificaram que, em sementes de Cassia bicapsularis, C. javanica e C. speciosa, quando submetidas ao tratamento com água quente a $100^{\circ} \mathrm{C}$, a dormência não foi superada. Da mesma forma, Eira et al. (1993) verificaram que a água quente a $100{ }^{\circ} \mathrm{C}$, com posterior resfriamento, também não foi eficiente para superar a dormência de sementes de Enterolobium contortisiliquum. Porém, Ulhôa e Botelho (1993), concluíram que a imersão em água quente a $100{ }^{\circ} \mathrm{C}$ fora do aquecimento, seguido de embebição por 24 a 48 horas é eficiente para superar a dormência de Senna multijuga. Deve-se considerar que o mecanismo de atuação da água quente para superar a dormência de sementes ainda não é bem conhecido. Deste modo, lotes de sementes de uma mesma espécie podem apresentar respostas diferentes quanto à sua utilização.

De acordo com os dados da Tabela 1, observou que quando se utilizou rolo-de-papel, as maiores percentagens de plântulas normais ocorreram quando as sementes foram submetidas à escarificação ácida por 20 minutos para ambos fotoperíodos, porém, verificou que o fotoperíodo de 24 horas obteve a maior percentagem de germinação (58,59\%). Souza et al. (2005) também constataram que o aumento do tempo de exposição ao ácido sulfúrico favoreceu o aumento da porcentagem de germinação, havendo uma relação direta entre tempo de imersão e porcentagem de germinação de Senna spectabilis. Medeiros Filho et al. (2005), obtiveram resultados semelhantes ao submeterem sementes de Caesalpinia ferrea à escarificaçáo química com ácido sulfúrico, para eliminação da dormência, com $82 \%$ de germinabilidade.

Quando foi utilizado vermiculita como substrato (Tabela 2) verificou que a utilização da escarificação ácida por 10 e 20 minutos, obtive os melhores resultados em ambos fotoperíodos. $\mathrm{O}$ ácido sulfúrico tem a função de escarificar quimicamente o tegumento tornando-o permeável à água. Segundo Barbosa et al. (2004) O tratamentos com ácido sulfúrico têm a vantagem de superar a dormência das sementes e reduzindo tempo do processo germinativo das sementes de Ochroma lagopus. 
Tabela 1 - Percentagem de plântulas normais, plântulas anormais, sementes duras e sementes mortas no teste de germinação de sementes de Senna multijuga submetidas a diferentes métodos de superação de dormência e dois fotoperíodos, no substrato rolo-de-papel.

\begin{tabular}{|c|c|c|}
\hline \multicolumn{3}{|c|}{ SUBSTRATO ROLO-DE-PAPEL } \\
\hline \multicolumn{3}{|c|}{ FOTOPERÍODOS } \\
\hline & 12 HORAS & 24 HORAS \\
\hline \multicolumn{3}{|c|}{ PLÂNTULAS NORMAIS (\%) } \\
\hline Testemunha & $0,00 \mathrm{C} \mathrm{b}$ & $1,48 \mathrm{C} \mathrm{a}$ \\
\hline Água quente $\left(100^{\circ} \mathrm{C}\right)$ & $0,00 \mathrm{C} \mathrm{b}$ & $0,13 \mathrm{D}$ a \\
\hline Escarificação ácida por 10 min. & $23,29 \mathrm{~B} \mathrm{a}$ & $20,34 \mathrm{~B} \mathrm{~b}$ \\
\hline Escarificação ácida por 20 min. & $53,00 \mathrm{~A} \mathrm{~b}$ & $58,59 \mathrm{~A} \mathrm{a}$ \\
\hline \multicolumn{3}{|c|}{ PLÂNTULAS ANORMAIS (\%) } \\
\hline Testemunha & $0,00 \mathrm{Db}$ & $1,46 \mathrm{C} \mathrm{a}$ \\
\hline Água quente $\left(100^{\circ} \mathrm{C}\right)$ & $4,35 \mathrm{C} \mathrm{b}$ & $7,21 \mathrm{~A} \mathrm{a}$ \\
\hline Escarificação ácida por 10 min. & $13,48 \mathrm{~B}$ a & $7,82 \mathrm{~A} \mathrm{~b}$ \\
\hline Escarificação ácida por 20 min. & $16,52 \mathrm{~A} \mathrm{a}$ & $6,47 \mathrm{~B} \mathrm{~b}$ \\
\hline \multicolumn{3}{|c|}{ SEMENTES DURAS (\%) } \\
\hline Testemunha & $98,74 \mathrm{~A} \mathrm{a}$ & $96,33 \mathrm{~A} \mathrm{~b}$ \\
\hline Água quente $\left(100^{\circ} \mathrm{C}\right)$ & $19,77 \mathrm{Db}$ & $28,44 \mathrm{C} \mathrm{a}$ \\
\hline Escarificação ácida por 10 min. & $51,00 \mathrm{~B} \mathrm{~b}$ & $65,31 \mathrm{~B} \mathrm{a}$ \\
\hline Escarificação ácida por 20 min. & $25,87 \mathrm{C} \mathrm{a}$ & $27,81 \mathrm{C} \mathrm{a}$ \\
\hline \multicolumn{3}{|c|}{ SEMENTES MORTAS (\%) } \\
\hline Testemunha & $1,25 \mathrm{D} \mathrm{a}$ & $0,00 \mathrm{C} \mathrm{b}$ \\
\hline Água quente $\left(100^{\circ} \mathrm{C}\right)$ & $73,70 \mathrm{~A} \mathrm{a}$ & $61,37 \mathrm{Ab}$ \\
\hline Escarificação ácida por 10 min. & $10,47 \mathrm{~B} \mathrm{a}$ & $4,11 \mathrm{~B} \mathrm{~b}$ \\
\hline Escarificação ácida por 20 min. & $3,00 \mathrm{C} \mathrm{b}$ & $6,15 \mathrm{~B} \mathrm{a}$ \\
\hline
\end{tabular}

* Medias seguidas pela mesma letra, maiúscula na coluna e minúscula na linha, não diferem entre si pelo teste de Tukey a $5 \%$ de significância.

Tabela 2 - Percentagem de plântulas normais, plântulas anormais, sementes duras e sementes mortas no teste de germinação de sementes de Senna multijuga submetidas a diferentes métodos de superação de dormência e fotoperíodos, no substrato vermiculita.

\begin{tabular}{|c|c|c|}
\hline \multicolumn{3}{|c|}{ SUBSTRATO VERMICULITA } \\
\hline \multicolumn{3}{|c|}{ FOTOPERÍODOS } \\
\hline & 12 HORAS & 24 HORAS \\
\hline \multicolumn{3}{|c|}{ PLÂNTULAS NORMAIS (\%) } \\
\hline Testemunha & $0,73 \mathrm{~B} \mathrm{a}$ & $0,50 \mathrm{C} \mathrm{a}$ \\
\hline Água quente $\left(100^{\circ} \mathrm{C}\right)$ & $2,51 \mathrm{~B} \mathrm{a}$ & 7,36 B a \\
\hline Escarificação ácida por 10 min. & $59,58 \mathrm{~A}$ a & $60,22 \mathrm{~A} \quad \mathrm{a}$ \\
\hline Escarificação ácida por 20 min. & $62,03 \mathrm{~A}$ a & $66,32 \mathrm{~A} \quad \mathrm{a}$ \\
\hline \multicolumn{3}{|c|}{ PLÂNTULAS ANORMAIS (\%) } \\
\hline Testemunha & $0,50 \mathrm{~B} \mathrm{a}$ & $0,50 \mathrm{~B}$ \\
\hline Água quente $\left(100^{\circ} \mathrm{C}\right)$ & $1,01 \mathrm{~B} \mathrm{a}$ & $1,46 \quad B$ \\
\hline Escarificação ácida por 10 min. & $6,64 \mathrm{~A} \quad \mathrm{~b}$ & $17,87 \mathrm{~A}$ \\
\hline Escarificação ácida por 20 min. & $9,37 \mathrm{~A}$ a & $15,72 \mathrm{~A}$ \\
\hline \multicolumn{3}{|c|}{ SEMENTES DURAS (\%) } \\
\hline Testemunha & $97,49 \mathrm{~A}$ a & $98,00 \mathrm{~A} \mathrm{a}$ \\
\hline Água quente $\left(100^{\circ} \mathrm{C}\right)$ & $95,00 \mathrm{~A} a$ & $89,97 \mathrm{~A}$ a \\
\hline Escarificação ácida por 10 min. & $31,38 \mathrm{~B} \mathrm{a}$ & $21,51 \mathrm{~B} \mathrm{a}$ \\
\hline Escarificação ácida por 20 min. & $28,48 \mathrm{~B} \mathrm{a}$ & $17,88 \mathrm{~B} \mathrm{a}$ \\
\hline
\end{tabular}

* Medias seguidas pela mesma letra, maiúscula na coluna e minúscula na linha, não diferem entre si pelo teste de Tukey a 5\% de significância. 
Segundo Figliolia et al. (1993), o substrato vermiculita tem a capacidade de retençáo de água, umidade e nutrientes transferíveis para as plantas, contribuindo o processo de germinação das sementes de $S$. multijuga. Porém, a alta capacidade de retenção de umidade do substrato também pode ter contribuindo para o aumento da morte das sementes dormentes devido ao ataque de microorganismos, patogênicos ou não, ocorrendo assim, um incremento na porcentagem de sementes mortas e zerando a porcentagem das sementes duras (Tabela 2).

Observou na Tabela 2, que não ocorreu diferença significativa entre os fotoperíodos de 12 e 24 horas para as diferentes variáveis analisadas, portanto, a espécie em estudo não sofreu interferência do fotoperíodo no processo de germinação quando se utilizou substrato vermiculita. Para plântulas anormais, não ocorreu diferença significativa entre a escarificação ácida por 10 e 20 minutos, assim como para os fotoperíodo de 12 e 24 horas, portanto, S. multijuga não apresentou uma exigência de fotoperíodo para a variável analisada, mas sim entre os diferentes métodos de superaçáo de dormência. Para Carvalho (2000) a germinaçáo das sementes em relação à luz é uma resposta ecofisiológica da espécie, que está correlacionada com o seu posicionamento no estádio sucessional da floresta.

No teste de tetrazólio (Tabela 3) foi verificado que não houve diferença significativa entre o método de superação de dormência por escarificaçáo ácida nos tempos 10 e 20 minutos, para as sementes classificadas como viáveis. Verificou que, também não ocorreu diferença significativa para a variável plântulas normais do teste de germinação (Tabela 2), quando as sementes foram submetidas a escarificação ácida, o que correspondeu à resultados do teste de tetrazólio (Tabela 3). A escarificação ácida por 20 minutos e a utilização da água quente $\left(100{ }^{\circ} \mathrm{C}\right)$ proporcionaram um aumento na porcentagem de sementes classificadas como intermediárias (Tabela 3), e o mesmo foi observados na Tabela 1, para a variável plântulas anormais. Quando se utilizou água quente, houve um aumento na porcentagem de sementes inviáveis. $\mathrm{Na}$ Tabelas 1 e 2, também foi constatada uma alta porcentagem de sementes mortas no teste de germinação, quando se utilizou água quente como método de superação de dormência.

Resultados semelhantes foram obtidos por Mendonça et al. (2001) que concluíram que diásporos de Cordia trichotoma quando imersos em soluçấo de tetrazólio a $0,25 \%$, durante duas a quatro horas a $40{ }^{\circ} \mathrm{C}$, permitem a obtençấo de resultados táo bons quanto o do teste de germinaçáo.

Ferreira et al. (2004), relatam que o teste de tetrazólio (concentração $0,075 \%$ e $30{ }^{\circ} \mathrm{C}$ ), com incubação por 5 horas, para S. multijuga, foi eficiente para avaliar o vigor e a viabilidade das sementes desta espécie, em laboratório ou provenientes do banco de sementes do solo.
Tabela 3 - Categorias de viabilidade do teste de tetrazólio de sementes de Senna multijuga submetida a diferentes métodos de superação de dormência.

\begin{tabular}{lllllllll}
\hline & Viáveis & & \multicolumn{4}{c}{ Intermediárias } & Inviáveis & \\
\hline Água quente $\left(100^{\circ} \mathrm{C}\right)$ & 8,08 & & B & 29,74 & A & 61,31 & A & \\
$\begin{array}{l}\text { Escarificação ácida } \\
\text { por 10 min. }\end{array}$ & 59,99 & A & 27,98 & B & 12,03 & B \\
$\begin{array}{l}\text { Escarificação ácida } \\
\text { por } 20 \text { min. }\end{array}$ & 58,53 & A & 29,74 & A & 11,44 & B \\
\hline
\end{tabular}

* Média seguidas pela mesma letra, maiúscula na coluna não diferem entre si pelo teste Tukey.

Os resultados da avaliação da qualidade sanitária das sementes de Senna multijuga são apresentados na Tabela 4. Observou a ocorrência de Fusarium spp., Aspergillus spp., Penicillium spp. e outros fungos, como, Alternaria spp. e Cladosporium spp. Além dos fungos já citados, Shultz et al. (2003), identificaram Helminthosporium sp., Ulocladium sp., Pestalotia sp., Trichoderma sp., Chaetomium sp. e Monilia sp. associados às sementes de Senna multijuga. Parisi et al. (2005), também constaram a presença desses fungos em sementes das espécies aroeira (Schinus terebinthifolius), canafístula (Peltoforium dubium), caroba (Jacaranda micrantha), cedro (Cedrela fissilis), figueira (Ficus enormes), guarantã (Piptadenia gonocantha), jacarandá-mimoso (Machaerium paraguariense), quaresmeira (Tibouchina sellowiana) e pau-marfim (Balfourodendron riedelianum).

Foi verificado que o controle de Fusarium spp. (Tabela 4) aumentou gradativamente com o aumento do tempo de exposição ao ácido sulfúrico concentrado.Fusarium spp., transmitido por sementes, tem sido relatado como um dos principais agentes da podridão radicular, doença que reduz significativamente a produtividade da cultura atacada (Mendes et al, 2002).

O uso da escarificação ácida por 10 minutos promoveu o aumento de Aspergillus spp. (49,0\%), porém, quando o tempo de exposição foi de 20 minutos, reduziu a percentagem $(5,62 \%)$. Portanto, aumento do tempo da exposição das sementes no ácido sulfúrico reduz a incidência de Aspergillus spp., que é considerado fungo de armazenamento, juntamente com Penicillium spp. Estes contaminam as sementes após a colheita e são fungos típicos apodrecedores.

Verificou que a incidência de Penicillium spp. aumentou gradativamente com o aumento da exposiçáo das sementes na escarificaçáo ácida. Portanto, a incidência de Penicillium spp. foi máxima (86\%) quando utilizou-se escarificação ácida por 20 minutos. Provavelmente, esse resultado ocorreu devido à presença de Penicillium spp. nos tecidos internos da semente, ou seja, a escarificação ácida, fez com que o fungo presente nos tecidos internos das sementes fosse liberado.

Carneiro (1986) cita a necessidade de dar maior atenção para o aspecto de sanidade de sementes de espécies florestais, visando à obtenção da melhoria da qualidade das sementes e mudas. 
Tabela 4 - Incidência de fungos associados às sementes de Senna multijuga, submetidas aos diferentes métodos de superação de dormência.

\begin{tabular}{lcccc}
\hline & Fusarium spp. & Aspergillus spp. & Penicillium spp. & 0utros \\
\hline Testemunha & $71,42 \mathrm{~A}$ & $6,76 \mathrm{~B}$ & $1,01 \mathrm{C}$ & $35,96 \mathrm{~A}$ \\
Água quente $\left(100{ }^{\circ} \mathrm{C}\right)$ & $0,00 \mathrm{D}$ & $0,00 \mathrm{D}$ & $0,00 \mathrm{D}$ & $0,00 \mathrm{C}$ \\
Escarificação ácida por $10 \mathrm{~min}$. & $42,90 \mathrm{~B}$ & $49,00 \mathrm{~A}$ & $24,79 \mathrm{~B}$ & $0,00 \mathrm{C}$ \\
Escarificação ácida por $20 \mathrm{~min}$. & $19,58 \mathrm{C}$ & $5,62 \mathrm{C}$ & $85,71 \mathrm{~A}$ & $4,00 \mathrm{~B}$ \\
\hline
\end{tabular}

* Média seguidas pela mesma letra, maiúscula na coluna, não diferem entre si pelo teste Tukey a $5 \%$ de significância.

Na Tabela 5, observa os dados referentes a avaliaçáo da qualidade de mudas de $S$. multijuga, quando as sementes foram submetidas aos diferentes métodos de superação da dormência. A utilização da água quente tornou as sementes inviáveis e resultados semelhantes foram encontrados no teste de germinação (Tabelas 1 e 2) e no teste de tetrazólio (Tabela 3). O método de superaçáo ácida por 20 minutos resultou em mudas de maior diâmetro de colo e apresentou o sistema radicular mais desenvolvido. Isso se deve à eficiência do método de superaçáo da dormência, que também foi observada no teste de germinação proporcionando um incremento nessa variável (Tabelas 1 e 2). Portanto, a escarificação ácida melhorou a qualidade das mudas, pois promoveu uma melhora na germinação das sementes. A escarificação ácida por 10 minutos resultou em um aumento na altura total, da parte aérea, e no peso da matéria seca das mudas. Provavelmente, o aumento da exposiçáo das sementes no ácido sulfúrico prejudica o desenvolvimento das plântulas. Segundo PiñaRodrigues (1988), o uso de sementes de alta qualidade é de grande importância para a instalação e produção de uma cultura, e a qualidade das mudas influência diretamente no estabelecimento de povoamentos florestais, obtendo-se sucesso ou não em programas de florestamento e reflorestamento.

$\mathrm{Na}$ avaliação do coeficiente de correlação entre as sementes mortas e Fusarium spp., foi verificado correlação negativa independente do método de superação de dormência, substrato e fotoperíodo utilizado. Portanto, Fusarium spp. não interfere no percentual de sementes mortas do teste de germinação sendo que esse patógeno é um agente causal de tombamento de plântulas e de doenças vasculares,

Resultados semelhantes foram observados para Aspergillus spp. e Penicillium spp. que podem causar apodrecimento de sementes e, consequentemente, perda na germinação. Verificou-se correlação negativa entre os fungos classificados como outros (Alternaria spp. e Cladosporium spp.) e sementes mortas do teste de germinação quando se utilizou o substrato rolo-de-papel, independente do método e superação de dormência e do fotoperíodo utilizado.

Cherobini et al. (2008), verificaram que as sementes de Cedrela fissilis apresentaram coeficiente de correlação negativo entre os diferentes fungos presentes nas sementes e as variáveis emergência de plantas no viveiro e comprimento das raízes, indicando assim, que esses fungos causam problemas, como o apodrecimento de sementes, que nem chegam a germinar, ocasionando uma redução na população de mudas, mas não interferindo na qualidade destas.

$\mathrm{Na}$ avaliação dos coeficientes de correlação entre os dados do teste de germinaçáo e teste de tetrazólio, foi observado correlação negativa entre plântulas normais e sementes viáveis $(r=-0,14$ e $r=-0,22$, respectivamente), independentemente do método de superaçáo de dormência e fotoperíodo utilizado no substrato vermiculita.

Foi observado correlaçáo positiva entre plântulas anormais do teste de germinação quando se utilizou substrato vermiculita no teste de germinação e sementes intermediarias do teste de tetrazólio ( $r=0,33$ e r= 0,1, respectivamente), para ambos fotoperíodos, indicando que o teste de tetrazólio pode ser utilizado como indicação da viabilidade intermediária das sementes de Senna multijuga.

Para fotoperíodo de 12 horas, foi verificado que a variável sementes mortas mostrou correlação negativa com as sementes inviáveis no teste de tetrazólio, indicando que para estas variáveis, o teste de tetrazólio não representa a real condição da viabilidade das sementes quando utilizou-se substrato vermiculita e qualquer método de superação da dormência.

Segundo Krzyzanowski et al. (1999), a escolha de metodologia adequada para o emprego do teste de tetrazólio deve se basear na facilidade para a diferenciação de tecidos viáveis e inviáveis e na capacidade de diferenciar a qualidade fisiológica

Tabela 5 - Avaliação da qualidade de mudas de Senna multijuga, submetidas aos diferentes métodos de superação de dormência.

\begin{tabular}{lccccc}
\hline & $1{ }^{* *}$ & 2 & 3 & 4 & 5 \\
\hline Testemunha & $0,00 \mathrm{C}$ & $0,00 \mathrm{C}$ & $0,00 \mathrm{C}$ & $0,00 \mathrm{C}$ & $0,00 \mathrm{C}$ \\
Água quente $\left(100^{\circ} \mathrm{C}\right)$ & $0,00 \mathrm{C}$ & $0,00 \mathrm{C}$ & $0,00 \mathrm{C}$ & $0,00 \mathrm{C}$ & $0,00 \mathrm{C}$ \\
Escarificação ácida por $10 \mathrm{~min}$. & $0,077 \mathrm{~B}$ & $14,70 \mathrm{~B}$ & $5,48 \mathrm{~A}$ & $3,78 \mathrm{~A}$ & $0,71 \mathrm{~A}$ \\
Escarificação ácida por $20 \mathrm{~min}$. & $0,094 \mathrm{~A}$ & $14,41 \mathrm{~A}$ & $4,79 \mathrm{~B}$ & $3,19 \mathrm{~B}$ & $0,68 \mathrm{~B}$ \\
\hline
\end{tabular}

*Média seguidas pela mesma letra, maiúscula na coluna, não diferem entre si pelo teste Tukey a $5 \%$ de significância.

$1^{* \star}$. Diâmetro do colo $(\mathrm{cm}), 2$. Altura total $(\mathrm{cm}), 3$. Comprimento da raiz $(\mathrm{cm}), 4$. Comprimento da parte aérea $(\mathrm{cm}), 5$. Peso da matéria seca $(\mathrm{g})$ 
de sementes. Portanto, o teste de tetrazólio pode ser usado como um complemento ao teste de germinaçáo em sementes.

No substrato rolo-de-papel e fotoperíodo de 24 horas, ocorreu correlação positiva $(\mathrm{r}=0,1)$ entre sementes classificadas como viáveis do teste de tetrazólio e plântulas normais do teste de germinação, indicando que o teste de tetrazólio pode ser utilizado como indicação da viabilidade das sementes.

Para fotoperíodo de 12 horas, a correlaçáo foi negativa ( $\mathrm{r}=$ $-0,14)$, entre sementes classificadas como viáveis no teste de tetrazólio e plântulas normais no teste de germinação.

Para a variável plântulas anormais do teste de germinação e intermediária no teste de tetrazólio, a correlaçáo foi negativa $(r=-0,6$ e $r=-0,16$, respectivamente), mostrando que o teste de tetrazólio não representa a viabilidade intermediaria das sementes de $S$. multijuga, quando utilizou-se substrato rolo-de-papel.

\section{CONCLUSÕES}

As sementes de Senna multijuga possuem dormência tegumentar e a escarificação ácida constituiu-se no método mais eficiente para a superação da dormência das sementes de S. multijuga.

O tratamento com água fervente aumenta a percentagem de sementes mortas.

Penicillium sp. e Aspergillus sp. tiveram sua incidência aumentada quando o tegumento foi danificado pela escarificação ácida por 20 minutos.

A escarificação ácida melhorou a qualidade das mudas de S. multijuga, devido à melhoria da germinaçáo das sementes.

\section{BIBLIOGRAFIA CITADA}

BARBOSA, A. P.; SAMPAIO, P. T. B.; CAMPOS, M. A. A.; VARELA, V. P. V; GONÇALVES, C. Q. B.; IIDA, S. 2004. Alternative technology for breaking seed dormancy pau-de-balsa (Ochroma lagopus Sw., Bombacaceae). Acta Amazônica. 34 (1): 107-110 (in Portuguese).

BEWLEY, J. D. 1997. Seed germination and dormancy. 9: 1055 -1066 (in English).

BIANCHETTI, A.; RAMOS, A. 1982. Comparison of treatments for breaking dormancy of canafistula seeds (Peltophorum dubium (Spreng.) Taubert.). Bol. Pesq. Florest. , Curitiba, 4: 91-99 (in Portuguese).

BRASIL. 1992. Rules for Testing Seeds. Ministério da Agricultura e Reforma Agrária. SNDA/DNPV/ CLAV. Brasília. 365pp (in Portuguese).

CARNEIRO, J. G. A. de1983. Variaçôes na metodologia de produção de mudas florestais afetam os parâmetros morfofisiológicos que indicam a sua qualidade. Curitiba: FUPEF, (FUPEF. Serie técnica n. 12), 40p (in Portuguese).

CARNEIRO, J. S. 1986. Mycoflora associated with seeds of forest trees. Fitopatologia Brasileira, Brasília, 11 (3): 557-66 (in Portuguese, with abstract in English).
CARVALHO, P., E., R. 2003 Tree species in Brazil.Brasília: Embrapa Informaçóes Tecnológica; Colombo, PR: Embrapa florestas, 1: 727-734 (in Portuguese).

CARVALHO, N. C. M.; NAKAGAWA, J. 1988 Sementes: Ciências, Tecnologia e Produçâo. Jaboticabal: FUNEP, 424pp (in Portuguese).

CHEROBINI, E. A. I.; MUNIZ, M. F. B.; BLUME, E. 2008. Assessment of quality of seeds and seedlings of cedro. Ciência Florestal, Santa Maria, 18 (1): 65-73 (in Portuguese, with abstract in English).

EIRA, M. T. S.; FREITAS, R. W. A.; MELO, C. M. C. 1993. Overcoming seed dormancy Enterolobium contortisiliquum (Vell.) Morong - Leguminosae. Revista Brasileira de Sementes, Brasília, 15 (2): 177-181 (in Portuguese, with abstract in English).

FERREIRA, R. A.; DAVID, A. C.; MOTTA, M. S. 2004. Vigor and viability of Senna multijuga (Rich.) Irwin et Barn. E Senna macranthera (Collad.) Irwin et Barn. seeds; a seed bank in soil salmon. Revista Brasileira de Sementes, 26 (1): 33-43 (in Portuguese, with abstract in English).

FIGLIOLIA, M. B.; OLIVEIRA, E. C; PIÑA-RODRIGUES, F. C. M. 1993. Seed Analysis. In: Aguiar, I. B. de; Piña-Rodrigues, F. C. M.; Figliolia, M. B. (Coord.). Tropical Forest Seeds. ABRATES. Brasília. p. 37-74 (in Portuguese).

KRAMER, P. J.; KOZLOWSKI, T. T. 1968. Physiology of trees. Lisboa, Calouste Gulbenkian, 745pp. (in Portuguese).

KRZYZANOWSKI, F. C.; VIEIRA, R. D.; NETO, J. de B. F. 1999. Seed vigor: Concepts and tests. Associaçáo Brasileira de Tecnologia de Sementes, Comitê de Vigor de Sementes. Londrina: ABRATES, 218pp. (in Portuguese).

SEBASTIÃO MEDEIROS FILHO, S.; SILVA, M. A. P.; SANTOS FILHA, M. E. C. 2005. Seed germination and seedling development Caesalpinia ferrea Mart. ex Tul var. ferrea in greenhouse and germination. Revista Ciência Agronômica, 36: (2): 203 - 208 (in Portuguese, with abstract in English).

MENDES, M. A. S.; LIMA, P. M. M. P.; FONSECA, J. N. L.; SANTOS, M. de F. 2002. Eradication Fusarium oxysporum seeds alfalfa using thermal and chemical treatments. Brasília: EMBRAPA-CNPF, 4p.(Documento,18) (in Portuguese).

MENDONÇA, E. A. F.; RAMOS, N. P.; PAULA, R. C. 2001. Viability of Cordia trichotoma (vellozo) Arrabida ex steudel (louropardo) by tetrazolium test. Revista Brasileira de Sementes, 23(2): 64-71 (in Portuguese, with abstract in English).

NASSIF, S. M. L.; PEREZ, S. C. J. G. A. 1997. Germination of amendoim-bravo (Pterogyne nitens Tul.): influence of treatments for breaking dormancy and sowing depth. Revista Brasileira de Sementes, Brasília, 19 (2): 172-179 (in Portuguese, with abstract in English).

PARISI, J. J. D.; ANDRADE, F. A.; COUTINHO, E. L.; BOTTOSSO, M. C.; MARTINS, M. C.; SALES, W. R. M. 2005. Sanitary quality of seeds and seedlings of native tree species of the state of São Paulo. In: $15^{\circ}$ CONGRESSO BRASILEIRO DE SEMENTES, 2005. Resumos. Foz do Iguaçu. CD... ABRATES, 2005 (in Portuguese). 
PIÑA-RODRIGUES, F. C. M. 1984. Prospects for using the test of aging in seeds of forest trees. In: 10 Simpósio Internacional: Métodos de Produção e Controle de Qualidade de Sementes e Mudas Florestais, Curitiba. Anais.... Curitiba: UFPR/IUFRO, p. 291313 (in Portuguese).

RODRIGUES, E.H.; AGUIAR, I.B.; SADER, R. 1990. Break dormancy of seeds of three species of the genus Cassia. Revista Brasileira de Sementes, Brasília, 12 (2):17- 27 (in Portuguese, with abstract in English).

SANTOS JÚNIOR, H.; NUNES, G. H. S.; GÓIS, F. C.; GUIMARĀES, I. P.; GRANGEIRO, L. C. 2005. Overcoming seed dormancy juca (caesalpinia ferrea mart. esc. tul). In: CONGRESSO BRASILEIRO DE SEMENTES, 2005, Resumos. Foz do Iguaçu. CD... ABRATES (in Portuguese).

SCHULTZ, V. S. 2003. Sanitary quality of seeds of pau-cigarra (Senna multijuga). Boletim Pesquisa Florestal, Colombo, 47: 123-128 (in Portuguese).

SOUZA, L. A.; MESQUITA, H. A.; ALVARENGA, M. I. N.; DAVIDE, A. C. 2005. Scarification chemical for breaking dormancy in Senna spectabilis seeds. In: $15^{\circ}$ CONGRESSO BRASILEIRO DE SEMENTES. Resumos. 2005. Foz do Iguaçu. CD... ABRATES . (in Portuguese).
SMIDERLE, O. J.; SOUSA, C. P. 2003. Dormancy of paricarana (Bowdichia virgilioides KUNTH - fabacea-Papilionidae). Revista Brasileira de Sementes, 25 (1): $72-75$ (in Portuguese, with abstract in English).

VARELA, V.P.; COSTA, S. S; BRAULE, M.; RAMOS, P. 2005. Influence of temperature and substrate on seed germination Itaubarana (Acosmium nitens (Vog.) Yakovlev) - Leguminosae, Caesalpinoideae. Acta Amazonica, Manaus, 35 (1): 35-39 (in Portuguese, with abstract in English).

ZONTA, E. P.; MACHADO, A. A. 1984. Statistical analysis system for microcomputers - SANEST. Pelotas: UFPEL, Registro SEI N, 066060-0, Categoria AO. (in Portuguese).

Recebido em 24/09/2008

Aceito em 27/10/2009 